\title{
Modelling Human Systems in Support of Process Engineering
}

\author{
Joseph O. Ajaefobi and Richard H. Weston \\ Loughborough University, MSI Research Institute, Leics LE 11 3TU, Loughborough, United \\ Kingdom. \\ Email: \{j.o.ajaefobi, r.h.weston\}@lboro.ac.uk
}

\begin{abstract}
There is a general requirement to resource the business processes of manufacturing enterprises with suitably structured human and technical systems. Further custom and practice is based upon specifying, building, utilizing and developing multiple human and technical systems so that they must be capable of interoperating in a customized way in order to concurrently fulfill the goals of multiple business processes. Various Enterprise Modelling techniques have been developed in recent decades which offer support for enterprise design and thereby help specify system requirements and solutions. However those techniques are generally known to be deficient in the support they provide for human systems engineering. This paper proposes means of characterizing the competencies and capacities of human resources, with reference to strategic, tactical and operational aspects of business processes. Also it explains how these 'models' of human resource can be deployed within the wider context of Enterprise Modelling to match the abilities and behaviors of stereotypical human systems to specific business process requirements.
\end{abstract}

Key words: Enterprise modelling, Business processes, Human systems engineering, Competencies, Capacities

\section{INTRODUCTION}

According to ISO 14258 (British Standards Institute 1998), three classes of activity are associated with plan/build, use/operate, and recycle/dispose life-phases of a Manufacturing Enterprise (ME). These classes of activity

1. decide what the ME should do (so called $W$ activities), 
2. decide how the ME should operate (so called $H$ activities) and

3. do those activities needed to realize products and services for customers

(so called $D$ activities), in conformance with $W$ and $H$ activity outcomes.

It follows that the business processes (BPs) of manufacturing enterprises (Mes) should comprise needed groupings of $W, H$ and $D$ enterprise activities.

It is also noted that invariably MEs realize their BPs by deploying a number of human and technical systems, the purpose of which is to structure and support the use of human and technical resources. Typically in any given $\mathrm{ME}$, the systems deployed need to interoperate in order to concurrently fulfill multiple BP goals in a timely and cost effective manner (WESTON 1999). The human systems (HSs) deployed commonly comprise structured groupings of people that may be supported by technology, and by so doing form ad hoc groups, teams, business units, departments or the complete ME.

Thus a general requirement to design a complex set of human and technical systems arises, so that in the short term MEs operate innovatively and competitively, and in the longer term MEs can reform and recompose themselves as product markets and environmental conditions change. A consequent need arises to match the abilities, capacities and availabilities of human and technical resources to functional and behavioral requirements of enterprise activities, and to do this sufficient knowledge of wider BP requirements in a given $\mathrm{ME}$ is needed so that valuable resources are appropriately and efficiently assigned and utilized.

Public domain enterprise Modelling EM concepts, architectures and methodologies such as CIMOSA (AMICE 1993), GRAI (CHEN, DOUMEINGTS 1996) IEM (VERNADAT 1996), PERA (WILLIAMS 1996) are known to provide means of decomposing, specifying, communicating, analyzing, visualizing and integrating complex enterprise requirements and thereby provide concepts to support the design of complex, interoperating resource systems. However, both theoretical and practical limitations have been observed in respect of the current solution provisions of EM concepts, particularly with respect to characterizing human systems and their potential roles in an enterprise (KOSANKE 2003; WESTON et al. 2003). Therefore this paper proposes and illustrates means of characterizing human resources, such that the potential of EM may be enhanced.

\section{AN OVERVIEW OF THE MEANING OF COMPETENCY}

ME processes (and their $W, H$ and $D$ elemental activities) interoperate to deliver products or services to specified customers within or outside the ME. These products or services are the observable measurable outcomes that can 
be judged in terms of their degree of excellence, timeliness and quantity. HSs are frequently deployed in association with other resources to realize process instances. An individual or a team is said to be competent with respect to any activity or process (or instance ${ }^{1}$ of these) if they satisfy prescribed requirements in a timely and cost effective manner. A competent individual (or team) can be trusted and relied upon to own an activity or process (i.e. by assigned responsibility) and to deliver the required products or services, other things being equal (AJAEFOBI 2004).

To understand the term competency, the following independent variables need to be kept in view: the activity (or process) to be executed competently; the required output (or activity performance) to be delivered at the desired level of competency; the HSs (and their elements) that come to the work with their available competencies. Bearing in mind the need to interrelate these variables within any ME context, the authors define the term "competency" as follows:

That property possessed by a HS that is willingly brought to bear on work, resulting in the effective and efficient delivery of the prescribed work outcomes.

Such a property possessed may encompass: natural traits (underlying traits), acquired competency (skills, experiences, education, trainings etc), adaptation competency (ability to adapt to new challenges and changes in job), and performing competency (i.e. ability to achieve an observable output). This view of competency builds upon observations of GARETH (1997) and thereby views competency from perspectives of: being (underlying traits), knowing (acquired skills, knowledge, experience) and doing (action or behavior that authenticates the other two).

The above definition also unifies two widely published but complementary views of competencies: namely

1. the input approach subscribed to by many US authors (BOYATZIS 1982) and

2. the output approach favored more in Europe (BROPHY, KIELY 2002).

Such a unification is required in MEs where it is necessary to define: Required Competencies (competencies necessary to achieve a purpose, mission, goal, objective, process, task or an activity) and Available Competencies that can be brought to bear to accomplish the required purpose, mission, etc (HARZALLAH, VERNADAT 2002). HSs especially teams can be classified with respect to the type of activities they execute as

Activity process execution has a defined "start", "body" and "end". Activities and processes may need to execute many times. Each time execution occurs this is referred to as an 'instance' 
strategic, tactical and operational teams (BYER, WESTON 2001). It follows that associated sets of competencies at strategic, tactical and operational levels of abstraction are required to match people to $W, H, D$ activities (and their parent processes) in MEs.

\section{MODELLING FRAMEWORK TO MATCH CAPABILITIES OF HUMAN SYSTEMS TO REQUIREMENTS OF ENGINEERING PROCESSES}

The MSI Research Institute, which operates out of the Wolfson School at Loughborough University (UK) has developed and tested an EM approach known as Multiple Process Modelling (MPM) method (CHATHA et al. 2003). Essentially, $M P M$ lends structure to the use of state-of-art public domain EM approaches by organizing:

1. the ongoing capture of a coherent and semantically rich picture of dependent processes, in such a way that key dependencies can explicitly be represented during the life time of dependent processes and

2 . the reuse of the multiple process models and their modeled dependencies for different enterprise engineering purposes.

Enterprise engineering projects can be supported by $M P M$ through a number of stages of model development and deployment. The different types of model created, developed and deployed is illustrated conceptually in Figure 1. Enterprise modelers and process and system engineers can move iteratively through modelling stages, developing and reusing model elements coherently as needed. MPM builds upon previously proven modelling concepts; this enables the capture of static, multi-perspective requirement models of a specified enterprise as well as means of creating dynamic requirement models, so that behaviors of candidate systems can be matched to defined requirements.

The first four modelling stages depicted by Figure 1 correspond to static model development. In MPM, CIMOSA concepts (AMICE 1993) have provided a backbone of modelling constructs onto which other new and previously established modelling concepts and constructs have (and can progressively be) connected. The backbone also allows model fragments (be they related to enterprise processes or enterprise systems) to be interpreted within a well-defined context. This content dependency was established because CIMOSA domain process, business process, enterprise activity and functional operation decomposition principles have been adopted and as 
appropriate that decomposition is reinforced by new $W, H$ and $D$ decomposition principles.

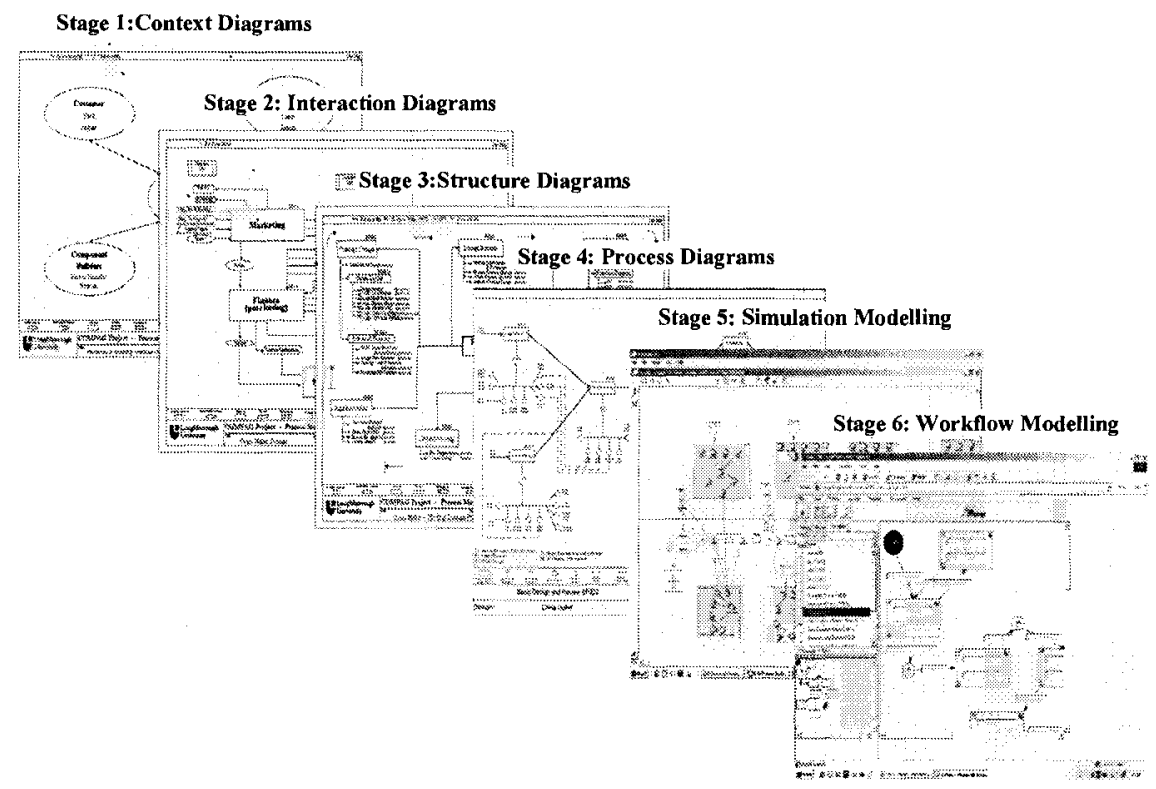

Figure 1. MPM modelling stages and formalisms

In the study reported in this paper the authors have exploited the eclectic capabilities of $M P M$ by extending its framework to include means of specifying, analysing and attributing competency constructs to $\mathrm{ME}$ processes, and by so doing have enabled the required competencies of elemental activities (that constitute a given process) to be formally described.

Further, it was proposed that all $W, H$, and $D$ activity types deployed by MEs can be represented in an abstract manner via the use of four semigeneric activity types (that can be particularized to suit specifics of any W, $\mathrm{H}$, and $\mathrm{D}$ context), so that groupings of activity can be resourced at suitable levels of modelling abstraction by a limited number of different classes of human system competency. The competency constructs conceived for such a purpose were designated CCL1 (Competency Class 1), CCL2, CCL3, and CCL4 and corresponding respectively to "simple operation", "skilled operation", "tactical operation" and "strategic operation" aspects. Table 1 illustrates examples of activities and their competency requirements as proposed. It was observed that HSs can posses these competency types as they interact with one another and competency possessed by other enterprise resource systems namely: technological (e.g. CNC machines and software applica- 
tions), structural (e.g. operating procedures and shared objectives) and transitional elements (e.g. information entities and process states) used to accomplish enterprise processes that collectively achieve defined goals.

Table 1 . Semi-generic competency classes and matching activity types

\begin{tabular}{|l|l|}
\hline Competency Class & \multicolumn{1}{|c|}{ Enterprise activity types } \\
\hline CCL 1 & $\begin{array}{l}\text { Competency to execute defined set of general } \\
\text { operations based on specified methods, proce- } \\
\text { dures and order. Here activities are essentially } \\
\text { routine and results predictable }\end{array}$ \\
\hline CCL 2 & $\begin{array}{l}\text { Competency to understand, interpret and } \\
\text { implement concepts, designs, and operation } \\
\text { plans linked to specific product realization and } \\
\text { to apply them in solving practical problems e.g. } \\
\text { system installation, operation and maintenance. }\end{array}$ \\
\hline CCL 3 & $\begin{array}{l}\text { Competency needed to translate abstract con- } \\
\text { cepts into shared realities in the form of product } \\
\text { designs, process specifications, operation pro- } \\
\text { cedures, budgeting and resource specifications }\end{array}$ \\
\hline CCL 4 & $\begin{array}{l}\text { Competency needed to formulating high level } \\
\text { business goals, mission, policies, strategies and } \\
\text { innovative ideas }\end{array}$ \\
\hline
\end{tabular}

A systematic approach to process resourcing was conceived in which available human competencies are matched to enterprise activity requirements at needed abstraction levels. This approach attributes modelling constructs (used to define competencies required from human resource systems) to models of enterprise activities and their associated functional operations ${ }^{2}$, in the manner shown conceptually by Figure 2 .

By such means semantically enriched models of processes can be captured, so as to more completely define process requirements. The addition of the competency modelling capability, and associated systemic approaches to matching required and available resource systems has been termed E-MPM (Enhanced-Multi Process Modelling method) because, essentially at modelling stage 4 of Figure 1, it builds upon and extends the modelling constructs incorporated into its predecessor $M P M$.

2 Activities are carried out by human and technical resources. Resources possess functional capabilities (often termed competencies in the case of human resources). Sometimes activities are described in terms of more elemental functional operations, the needed capabilities of which can be matched to functional capabilities possessed by resources. 


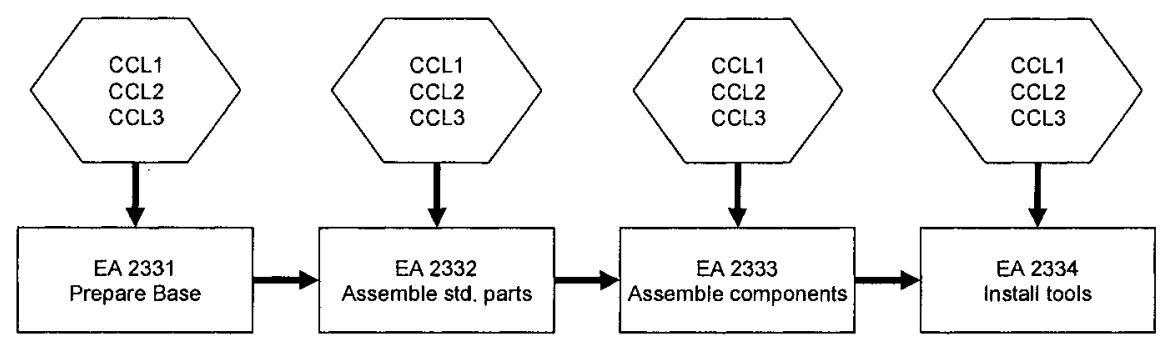

Figure 2. Conceptual illustration of the "attachment" of required competencies to enterprise activities ${ }^{3}$

E-MPM therefore integrates the use of MPM, CIMOSA and new HS concepts, constructs and modelling templates in such a way that complex engineering processes can naturally be grouped into organized groupings of enterprise activities (EAs) and functional operations (FOs), for which competency requirements can be formally specified. Also as an integral part of E-MPM a Hierarchical Task Analysis (HTA) technique (SHEPHERD 2000) can be applied to further decompose functional operations into elemental operations (things to do) and plans (how to do them). By such means needed human competencies can be encoded at four levels of abstraction corresponding to generic competencies required to satisfy general operational, skilled operational, tactical, and strategic activity needs, also illustrated by Figure 2 (see footnote). This naturally leads to an enriched graphical representation of business process (BP) models that supports a first stage matching of available HS competencies to BP competency requirements. The enterprise activities illustrated by Figure 2 are a small subset of activities that belong to a multi-process model of a case study company encoded using the first four modelling stages of MPM, as described in greater detail in AJAEFOBI (2004). This particular case study company is a vendor of production machines and systems. Primarily they build these machines and systems in conformance with requirements specified by customer contracts (or orders).

This first stage of resource matching is illustrated conceptually by Figure 3 where specified classes of CCL requirement (attributed to processes, activities and functional operations ${ }^{4}$ ) are matched to CCL abilities possessed

3 The nature of this particular process is such that in this case needed strategic competencies (normally attributed to CCL4) can be covered by aspects of tactical and operational competencies. In Figure 2 the abbreviation EA is used to denote an Enterprise Activity.

4 The reader should note that processes comprise more elemental sub-processes and activities, while activities comprise more elemental functional operations. These levels of process decomposition facilitate matching of processes to needed resources at multiple levels of abstraction. 
by candidate human resource systems, thereby enabling selection from amongst candidate systems to determine those that are viable candidates and those that are not. During this first matching stage therefore center of attention is on deciding whether HSs have the ability to do the jobs at hand. However at this stage no consideration is given to secondary concerns about the capacity of suitable resources to achieve activities in finite time frames. Nor at this stage is attention paid to the possibility that activity requirements might be concurrent or be subject to change.

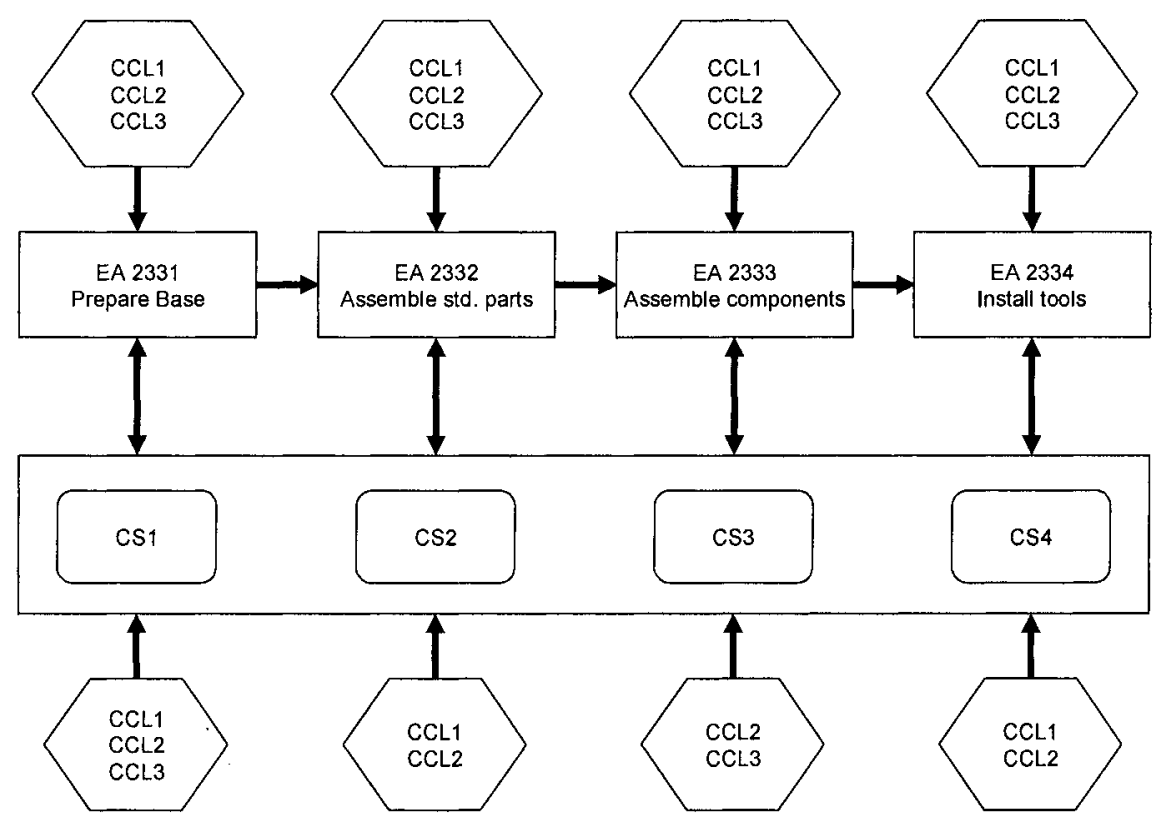

Figure 3. Conceptual illustration of stage 1 "Competency-Based Selection of Candidate Systems" (CS) - see also footnote 3

In general, it is envisaged that changes in job requirements will occur in two possible ways, namely

1. planned and anticipated changes and

2. unplanned and unanticipated changes.

It was observed that changes in job requirements (e.g. process specifications) can impact significantly on the adequacy of available human competencies. Therefore a second stage of matching was observed as being needed, during which competency behaviors could be simulated dynamically with a view to addressing issues like: 
a) How can viable candidate systems react to changes in job competency requirements?

b) Can competencies of the viable candidates handle effectively current and predicted requirements?

Hence the simulation modelling capabilities of $M P M$ were also enhanced at its modelling stages, so as to create $E-M P M$ which supports a second stage of human resource matching based upon dynamic (process and system) modelling.

During this second stage of human resource system selection, computer executable models of activity requirements and candidate human resources are recoded, using modelling constructs provided by the ithink dynamic systems simulation tool (ITHINK 2002). To encode "capacity" information in a generic and reusable manner, HS workload modelling concepts were conceived.

\section{WORKLOAD CONCEPT IN MATCHING TASKS TO HUMAN SYSTEM}

It was determined that workload (WL) modelling concepts and constructs needed to be deployed to enable dynamic assessment to be made about the competencies and capacities of human resources, with respect to their assigned roles under different conditions of load. In the example case study company referred to in the previous section, it was necessary to consider workload (WL) constraints arising from concurrent instances of the design and build processes used to make manufacturing machines for various customers. A given HS may be competent to undertake one or more operations but the imposition of WL constraints can impair the effectiveness and timeliness of needed activity and process outputs. Literature on WL was reviewed with focus on a consideration of mental WL concerns, and particularly upon total attentional demands on HSs of an assigned activity or operation (ALDRICH et al. 1989; NORTH and RILEY 1989; WICKENS 1984).

Based on the literature reviewed, a set of WL constructs was defined to characterize enterprise activities in the following respects: operational criticality, $O C$ (the significance the operation to entire process completion), operational demands, $O D$ (sensory modalities and conflicts that may occur during execution), operational uncertainty, $O U$ (availability and accessibility of needed information), operational precision, $O P$ and temporal demand, $\operatorname{Tr} / \mathrm{Ta}$. Subjective ratings of 1.0 to 7.0 were attached to these WL constructs, with 7.0 denoting very high pressure and a likelihood that performance break down might occur. Humans are capable of handling operations requiring concurrent responses in accordance with a "multiple resource" theory 
(WICKENS 1984) but greater risk of performance breakdown occurs when the use of common sensory modalities arise (NORTH, RILEY 1989) such as where there is simultaneous demand in respect to visual operations. Knowledge of WL issues was found to support the design of and selection between alternative candidate HS, on grounds of their capacity to do different classes of enterprise activity.

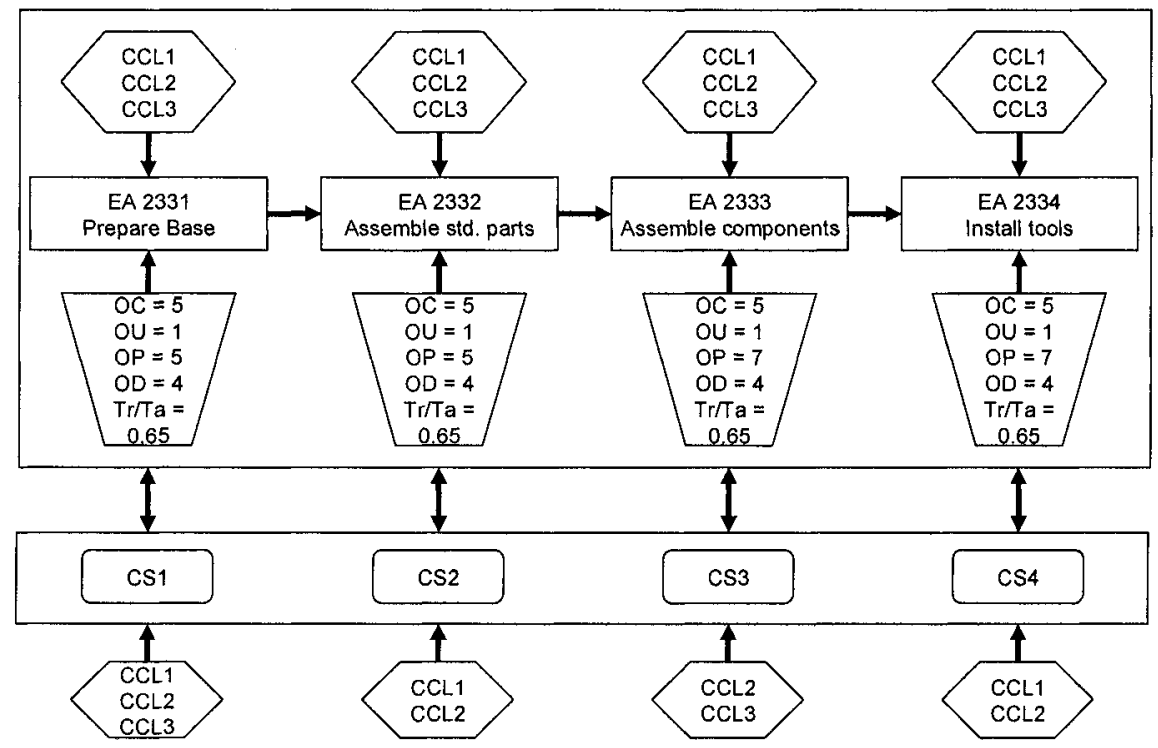

Figure 4. Conceptual illustration of the attachment of workload modelling constructs to enterprise activities ${ }^{5}$

(Source: AJAEFOBI, WESTON 49)

Figure 4 illustrates conceptually how WL modelling constructs were attached to graphical process models. As mentioned previously at the fifth modelling stage these enriched ME process models are recoded using the ithink tool. Figure 5 illustrates such an ithink model, which is a simulation model, corresponding to earlier models shown in Figures 2 and 3.

Whereas Figure 6 shows one of many forms of predicted performance information which can be generated during selection stage 2 , so as to enable the dynamic performance of viable human system candidates (selected out during selection stage 1) to be contrasted and compared, primarily on grounds of their timeliness and/or cost effectiveness.

5 The additional graphical modeling constructs attached to enterprise activities illustrates the ratings (on a scale of 1 to 7 ) attributed to workload (WL) constructs. 


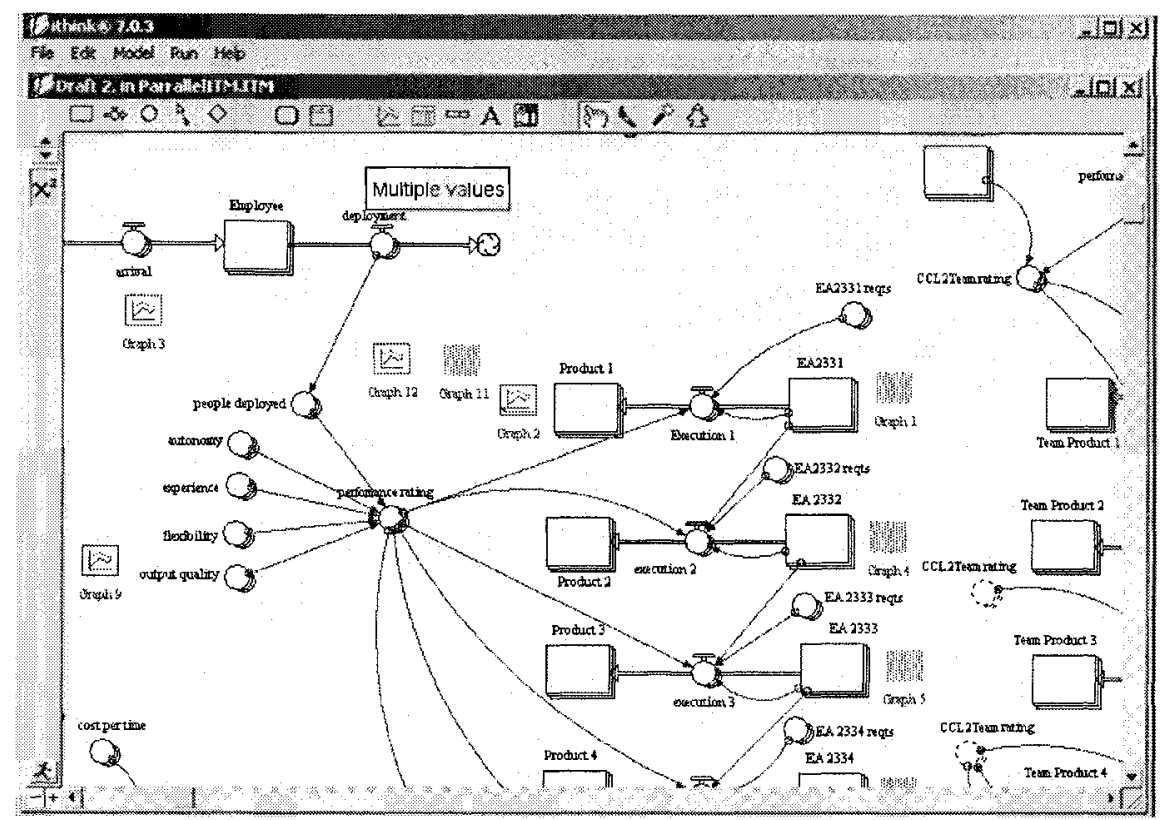

Figure 5. Illustrative extract from a semi-generic ithink model created to support second stage HS selection on grounds of dynamic performance measures

ithink was selected as the simulation tool because its underlying approach to modelling system dynamics characterizes complex systems as a set of interdependent differential equations. These equations are created and parameterized in a fairly user friendly way, via graphical modelling constructs. The equations are solved when simulations are run using a Numerical Integration technique and a set of input/output devices.

Of course other types of simulation tool could have been selected and deployed to fulfill requirements of the fifth stage of MPMIE-MPM modelling. But bearing in mind the need to quantify process lead times and costs when deploying alternative candidate resource systems, use of the ithink tool was found to provide appropriate support for decision making.

\section{CONCLUSION}

The paper describes in outline how a multiple process modelling method was enriched via the provisions of HS modelling concepts. It also explains how the enriched modelling method facilitates a two stage matching of HSs in terms of static competency modelling and dynamic capacity modelling. The modelling facility so developed has been shown to be capable of sup- 
porting business process engineering, by comparing alternative ways of resourcing activities and operations from both lead time and cost perspectives. Application of the competency and capacity modelling concepts, constructs and systemic approaches has been outlined when resourcing complex engineering activities in an example build-to-order (BTO) manufacturing business.

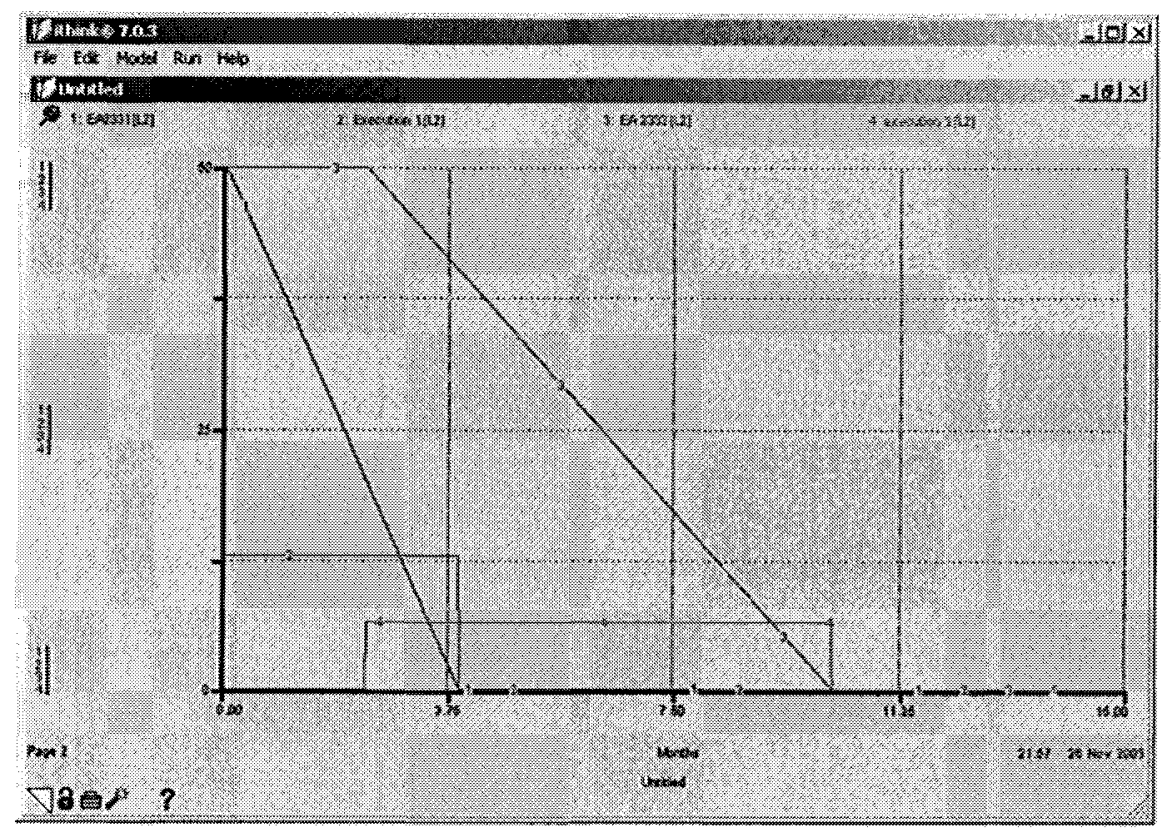

Figure 6. Illustrative dynamic performance information, predicted by running the semigeneric ithink model with specific HS competency and capacity model attributes assigned

AJAEFOBI (2004) describes in greater detail how HS modelling concepts reported in this paper have been used to enhance $M P M$ and thereby enable improved matching of specified groupings of engineering activities to organized systems of available human resources. It has been observed that two stage selection can be made between candidate individuals, teams and workgroups, on joint grounds of competency and workload capacity to realize requirements within defined cost and time constraints. Further, at stage six of $M P M / E-M P M$ application, off-the-shelf workflow technology can be deployed to enact computer executable models of the process flows created at earlier modelling stages. Thereby specification and management of BTO (and other) workflows can be enabled, so that programmable organizational structure is overlaid onto the collective working of structured units of engineering personnel. 


\section{REFERENCES}

\section{AJAEFOBI, J.O.:}

Human Systems Modeling in Support of Enhanced Process Realisation.

Loughborough, University PhD thesis, 2004.

AJAEFOBI, Joseph O.; WESTON, Richard H.:

An Approach to Modelling and Matching Human System Competencies to Engineering

Processes.

In: Human Aspects in Production Management.

Eds.: ZÜLCH, Gert; STOWASSER, Sascha; JAGDEV, Harinder S.

Aachen: Shaker Verlag, 2003, pp. 46-52.

(esim - European Series in Industrial Management, Volume 5)

ALDRICH, T. B.; SZABO, S. M.; BIERBAUM, C. R.:

The Development and Application of Models to Predict Operator Workload.

In: Applications of Human Performance Models to System Design.

Eds.: McMILLAN, G. R. et al.

London: Plenum Press 1989, pp. 65-80.

BOYATZIS, R. E.:

The Competent Manager: a model for effective performance.

New York, NY: Willey, 1982.

BROPHY, M.; KIELY, T.:

Competencies: a new sector.

In: Journal of European Industrial Training,

Bradford, 26(2002)2, pp. 165-176.

CHATHA, K. A.; WESTON, R. H.; MONFARED, R. P.:

An Approach to Modelling Dependencies Linking Engineering Processes.

In: Journal of Engineering Manufacture,

London, 217(2003)B5, pp. 669-687.

CHEN, D; DOUMEINGTS, G.:

The GRAI-GIM reference model, archtecture and methodology.

In: Architectures for Enterprise Integration.

Eds.: BERNUS, P. et al .

London et al : Chapman \& Hall, 1996 pp.103-126.

CIMOSA:

Open System Architecture for CIM..

Ed.: AMICE-ESPRIT Consortium.

Berlin: Springer Verlag, 2nd edition, Volume 1, 1993.

GARETH, R.:

Recruitment And Selection A Competency Approach.

London: Chartered Institute of Personnel and Development (CIPD), 1997.

HARZALLAH, M.; VERNADAT, F.:

IT-based competency modelling and management: from theory to practice in enterprise engineering and operations.

In: Computers in Industry, Amsterdam, 48(2002)2, pp. 157-179.

ISO 14258:

Industrial automation systems - Concepts and rules for enterprise models.

September 1998.

ITHINK: ithink( $($ Version 7.

Lebanon: High Performance Systems Inc., 2002. 
KOSANKE, K.:

Standardisation in Enterprise inter and intra Organisational Integration.

In: Proceedings of 10th Int. Soc. for Productivity Enhancement international conference on Concurrent Engineering: The Vision for the Future Generation in Research and Applications.

Eds.: JARDIM-GONCALVES, R. et al.

Lisse: Swets \& Zeitlinger, 2003, pp. 873-878.

NORTH, R. A.; RILEY, V. A.:

W/INDEX: A Predictive Model of Operator Workload.

In: Applications of Human Performance Models to System Design.

Eds.: McMILLAN, G. R. et al.

London: Plenum Press 1989, pp. 81-89.

SHEPHERD, A.:

Hierarchical Task Analysis.

London: Taylor \& Francis, 2000.

VERNADAT, $F$ : :

Enterprise modeling and integration: principles and applications.

London et al.: Chapman \& Hall, 1996.

WICKENS, C. D.:

Engineering psychology and human performance.

Columbus, OH: Bell and Howell Company, 1984.

WILLIAM, T. J.:

An Overview of PERA and the Purdue Methodology.

In: Architectures for Enterprise Integration.

Eds.: BERNUS, P. et al.

London et al.: Chapman \& Hall, 1996, pp. 129-161.

WESTON, R. H.; BYER, N.; AJAEFOBI, J.O.:

EM in support of team system engineering.

In: Proceedings of 10th Int. Soc. for Productivity Enhancement international conference on Concurrent Engineering: The Vision for the Future Generation in Research and Applications.

Eds.: JARDIM-GONCALVES, R. et al.

Lisse: Swets \& Zeitlinger, 2003, pp. 865-872.

WESTON, R. H.:

A Model-Driven, Component-Based Approach to Reconfiguring Manufacturing Software Systems.

In: International Journal of Operations and Production Management,

Bradford, 19(1999)8, pp. 834-855. 